\title{
Insights into the pollination requirements of the only African wild tobacco, Nicotiana africana (Solanaceae) from the Namib Desert
}

\author{
D. Marlin ${ }^{a}$, S.W. Nicolson ${ }^{\text {a }}$, J.D.S. Sampson ${ }^{b}$, K. Krüger ${ }^{\text {a, * }}$ \\ a Department of Zoology \& Entomology, University of Pretoria, Private Bag X20, Pretoria 0028, South Africa \\ b Manie van der Schijff Botanical Gardens, University of Pretoria, Private Bag X20, Pretoria 0028, South Africa \\ *Corresponding author. \\ E-mail address: kkruger@zoology.up.ac.za (K. Krüger).
}

Keywords:

Alkaloids

African tobacco

Namib Desert

Nectar

Pollination

Sunbird

\begin{abstract}
A B S T R A C T
Nicotiana species (Solanaceae) are widely distributed, mainly in the Americas and Australia. Nicotiana africana is the only species indigenous to Africa; its populations are confined to isolated mountains in the Namib Desert and thus little is known about this species' reproductive strategy or reliance on pollinators, if any. Plants grow in a sheltered environment among granite boulders and wind pollination is therefore unlikely. Our aim was to use a controlled hand-pollination experiment to identify the pollination requirements of $N$. africana and thereby infer the level of reliance on pollinators. One of five treatments was applied to flowers: either self- or cross-pollination, with half the flowers being emasculated and half not, and the fifth treatment consisted of unmanipulated flowers. Fruit set, seed set and seed weight were measured to determine pollinator reliance. Fruit set and seed set were similar for crossed and selfed flowers. Our findings show that $N$. africana is self-compatible but also partially dependant on pollinators for reproduction. Using floral traits, the plant's natural distribution and comparisons with other Nicotiana species, we predict that sunbirds (Nectariniidae) are the most likely pollinators of this species in its natural habitat.
\end{abstract}

\section{Introduction}

Of the about 80 recognised species of Nicotiana, an estimated $75 \%$ occur naturally in the Americas and $25 \%$ in Australia (Goodspeed, 1954). However, in the otherwise exclusively Australian section Suaveolentes, a single species is endemic to Africa (Knapp et al., 2004). Nicotiana africana Merxm. is found in very arid karroid shrubland in a semi-desert/desert environment in the arid Erongo, Spitzkoppe and Brandberg Mountains in the northwestern Namib Desert (Craven, 2004). It occurs in small isolated stands and grows in deep shade among granite boulders (Craven, 2004). It is not known what herbivores and/or pollinators are associated with this species in its natural habitat. Wind pollination is very unlikely in this sheltered environment.

$N$. africana is a sturdy perennial that can grow up to $2.5 \mathrm{~m}$ high. Its inflorescences (Fig. 1) are terminal panicles, each with 5-10 pale greenish white flowers that open by day (Herman, 1990). Nornicotine is the main alkaloid of the leaves and roots (Saitoh et al., 1985); nornicotine also occurs in the floral parts, but only at low concentrations, and the nectar does not contain nicotine, nornicotine or anabasine (Marlin et al., 2014). Furthermore, N. africana lacks a distinct floral scent, although the flowers of hummingbirdand hawkmoth-pollinated Nicotiana species have been shown to share floral volatiles, regardless of pollinator affinity (Raguso et al., 2003, 2006).

Three main pollination systems have been reported for Nicotiana species; hawkmoths, hummingbirds and sunbirds, and other pollinators such as bumblebees and small moths (Kaczorowski et al., 2005). Species of Nicotiana show interspecific variability in nectar volume and concentration (Kaczorowski et al., 2005) and in floral odour complexity and emission rates (Raguso et al., 2003, 2006), and this may influence pollinator preferences. Although certain species of Nicotiana are capable of self-pollination and others are not (Kaczorowski et al., 2005; Raguso et al., 2003; Adler et al., 2012), in many species seed production is significantly higher when the plants are exposed to pollinators (Geerts and Pauw, 2009; Schueller, 2004).

Adler et al. (2012) examined the pollinator reliance and alkaloid levels of 32 species of Nicotiana, excluding $N$. africana, and found that the nectar, floral and leaf nicotine concentrations were significantly lower in outcrossing than in selfing species. It has been 


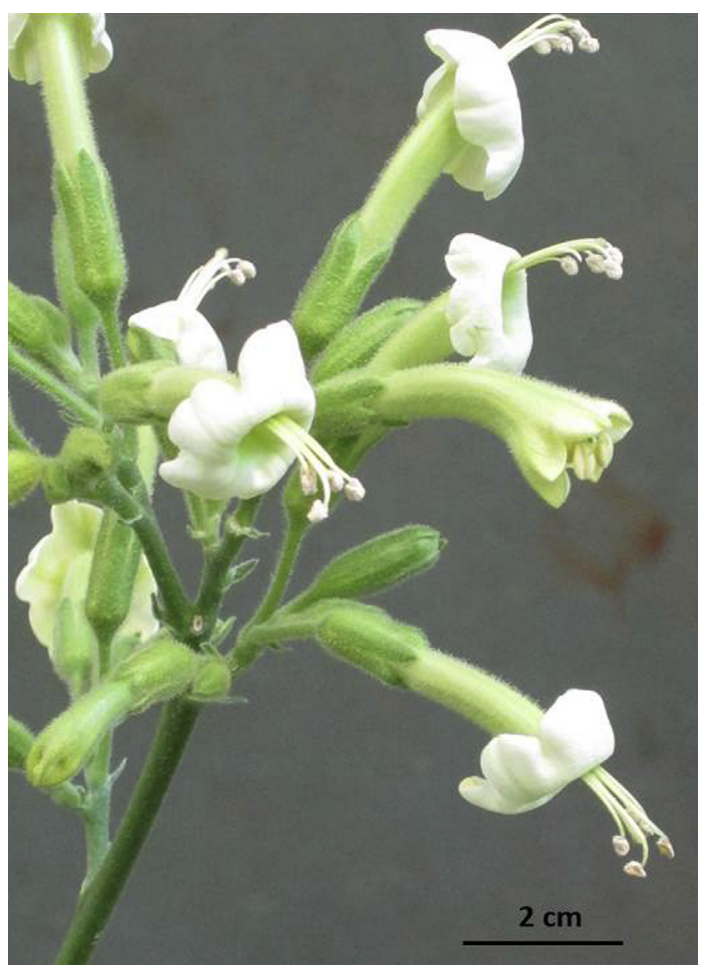

Fig. 1. The inflorescence of Nicotiana africana.

hypothesized that the rate of outcrossing among flowers increases as nectar nicotine levels decrease, because pollinators search for nectar with low nicotine concentrations, thereby moving between flowers and transferring pollen more frequently (Kessler et al., 2012). Due to their bitter taste, nectar alkaloids such as nicotine deter pollinators (Adler, 2000) whose flower visits would presumably increase plant reproduction. However, nicotine does not deter all pollinators: sunbirds are willing to drink sucrose solutions containing moderate concentrations of nicotine, despite being less tolerant of this alkaloid than other bird species (Lerch-Henning and Nicolson, 2013).

We determined the potential breeding system of $N$. africana as selfing or outcrossing, to ascertain whether this species is reliant on a pollen vector. We hypothesized that, due to the plant's highly isolated natural distribution and the harsh environment where it occurs, $N$. africana will show little reliance on pollinators and is likely to be self-compatible. Considering the rarity and remote desert location of this species, field work was not a practical option and we opted for the controlled environment of a glasshouse.

\section{Materials and methods}

Seeds were originally obtained from T. Doroszewska (Institute of Soil Science and Plant Cultivation, State Research Institute, Pulawy, Poland). The methods for propagating and maintaining N. africana plants were described in Marlin et al. (2014). For the present study, the pollination experiment began in January 2013 when the first plants started flowering and continued until September 2013 in order to obtain a sufficient number of replicates. The glasshouse was free of natural pollinators. Plants were maintained at $20.05 \pm 0.42{ }^{\circ} \mathrm{C}($ mean $\pm \mathrm{SE})$ and a relative humidity of $52 \pm 1 \% \mathrm{RH}$.

Flowers were allocated the following hand-pollination treatments: 1) unmanipulated (no emasculation, no pollination by hand), 2) emasculated untreated (emasculated but not pollinated),
3) crossed, 4) emasculated crossed, 5) selfed and 6) emasculated selfed. Because flowers did not mature simultaneously, each experimental plant was used for 2-4 treatments, assigned randomly, as flowers became available. Treatments within plant combinations therefore differed between plants (12 in total). Treatments were chosen to ensure that all possible scenarios were accounted for. Each treatment was replicated five times, and a minimum of 10 flowers was sampled per replicate.

Emasculation was carried out shortly after anthesis, but before the anthers had dehisced, to eliminate the possibility of natural self-pollination. As soon as the flowers opened, the still intact anthers were carefully removed by hand and kept in marked glass vials where they were allowed to mature until they had dehisced and released pollen; vials were stored in a dark and cool room. This pollen was then used for pollinating flowers, either on the same plant (selfed and emasculated selfed treatments), or on different plants (crossed and emasculated crossed treatments). We used a fine camel hair paintbrush, washed with distilled water between flowers and dried, to transfer pollen to receptive stigmas, usually between $0900 \mathrm{~h}$ and $1100 \mathrm{~h}$. Flowers in the selfed and outcross treatments were pollinated before anthers started to release pollen, to ensure that either pollen from the same plant, in the case of selfed flowers, or pollen from a different plant, in the case of outcrossed flowers, was the first pollen to come into contact with the stigma. Each flower was pollinated once only.

Mature fruits (capsules) were collected before they released their seeds, approximately 30 days after the flower first opened, and dried at $50{ }^{\circ} \mathrm{C}$ for at least $48 \mathrm{~h}$. Data for fruit set are based on the number of capsules that reached maturity, i.e. produced seeds, compared with the original number of flowers collected, and are presented as percentages. We recorded the number of flowers aborted in each treatment during the study period. Immature fruit abortion was high in the emasculated unmanipulated treatment (only seven flowers in this treatment were not aborted), and therefore this treatment was excluded from further analyses. Aborted flowers did not produce seeds. For each mature fruit we measured seed set (number of seeds produced per fruit), and thereafter the mean seed weight was calculated for each treatment on each plant. Seed set data were used to calculate the selfcompatibility index ( $\mathrm{SCI}=$ emasculated selfed/emasculated crossed) and self-fertility index (SFI = unmanipulated/emasculated crossed) (Lloyd and Schoen, 1992; Schoen and Lloyd, 1992).

The percentage fruit set data were arcsine transformed to meet the requirements of normality and homogeneity, and thereafter a one-way ANOVA was used to determine whether there were differences in fruit set between pollination treatments. Seed set was analysed with a generalized linear mixed model (Schall, 1991) with a Poisson distribution and a log link function. The mean seed weight between the pollination treatments was analysed with linear mixed model analysis (REML) (Payne et al., 2012). For both tests pollination treatment was included as fixed and plant as random effect. Fisher's protected LSD test was used to separate means at the $5 \%$ level of significance $(P<0.05)$. Data were analysed with GenStat ${ }^{\circledR} 2012$.

To predict the pollination mode of $N$. africana, we determined which treatment had the highest reproductive fitness, i.e. highest fruit set, seed set and mean seed weight.

\section{Results and discussion}

Abortion of immature fruit was high throughout the study and the percentage fruit set (percentage of flowers that produced seeds) differed significantly among treatments $\left(\mathrm{F}_{4,20}=2.966, P=0.045\right)$. It was significantly lower in the unmanipulated flowers compared to the other treatments (Fig. 2A). 



Fig. 2. Reproductive fitness of Nicotiana africana (means \pm SE): (A) Fruit set, (B) seed set and $(C)$ mean seed weight. Bars with the same letter above them are not significantly different (Fisher's LSD test, $P<0.05$ ). Fruit set: $n=5$ plants per treatment; seed set and seed weight: $n=50$ flowers per treatment. $\mathrm{U}=$ unmanipulated, $\mathrm{CR}=$ crossed, $\mathrm{ECR}=$ emasculated crossed, $\mathrm{S}=$ selfed, $\mathrm{ES}=$ emasculated selfed.

Seed set was significantly higher in the cross-pollinated and selfed than in the unmanipulated treatment, and the only other significant difference in seed set was between the selfed and emasculated crossed treatments (Wald $X^{2}=18.23, P=0.001$; Fig. 2B). The mean seed weight in the emasculated selfed treatment was significantly lower than that of the selfed treatment (Wald $X^{2}=15.38, P=0.005$; Fig. 2C). There were no significant differences for the other treatment combinations (Fig. 2C). Across all treatments, excluding the emasculated untreated treatment, plants produced $246.18 \pm 5.72$ seeds per fruit with a mean seed weight of $0.073 \pm 0.001 \mathrm{mg}$ (mean $\pm \mathrm{SE}$ ). The $\mathrm{SCI}$ index was 0.89 , indicating that $N$. africana is partially self-compatible, and the SFI index was 0.94 , suggesting that the plant is only partially selfing.

Fruit set and seed set were used to quantify pollinator reliance according to the categories of Adler et al. (2012) as follows: a) plants highly reliant on pollinators would be self-incompatible and show no or little fruit set in the unmanipulated and selfed treatments, b) plants with intermediate reliance on pollinators would be selfcompatible but show increased reproduction when pollen (selfed and/or crossed) was transferred via a vector, compared to the unmanipulated treatment, and c) plants with little reliance on pollinators would be highly selfing and supplemental self or outcrossed pollen would not significantly increase reproduction compared to the unmanipulated treatment. Using these pollinator reliance categories, we predict that $N$. africana has an intermediate reliance on pollinators, based on the findings that this species is selfcompatible (seeds were produced in the selfed treatments) but fruit and seed set were higher in the crossed treatments compared to the unmanipulated treatment (Fig. 2A, B).

Pollination is much better understood for the American species of Nicotiana than the Australian members of the genus. Based on the comparison of seed set between unmanipulated and selfed flowers, $N$. africana is self-compatible; this is supported by the SCI and SFI indices which indicate that the plant is self-compatible and partially autogamous, respectively. However, fruit and seed set are higher when the plants are cross pollinated than in unmanipulated flowers, a common pattern in Nicotiana (Adler et al., 2012). Our findings that cross pollinated flowers produced more seeds than unmanipulated flowers, and that the nectar of $N$. africana contains no alkaloids and the floral tissues only low concentrations of nornicotine (Marlin et al., 2014), are in partial agreement with the hypothesis of Adler et al. (2012) that species of Nicotiana fertilized through cross-pollination have low alkaloid levels in floral tissues and nectar. The complete absence of nectar alkaloids in $N$. africana, even after herbivory (Marlin et al., 2014), is more suggestive of high reliance on pollinators (Adler et al., 2012).

$N$. africana can use both self and cross-pollination as a means of reproduction. Whilst we did not test whether outcrossed pollen was advantageous over self pollen, cross-pollinated flowers produced slightly more seeds than self-pollinated flowers and herkogamy (the separation of the style and anthers either spatially or temporally or both) can be used by flowers to reduce selfpollination (Galetto and Bernardello, 1993; Willmer, 2011). In newly-opened $N$. africana flowers the stigma is positioned above and away from the anthers (Fig. 1), but two days later the anthers surround the style (D. Marlin pers. obs.), suggesting the opportunity for cross-pollination before self-pollination can occur.

All except seven emasculated untreated flowers were aborted by the plants without producing seeds, indicating that $N$. africana is not agamospermous i.e. cannot produce seeds from unfertilized ovules, and apomixis is therefore not a reproductive strategy of this species. On the other hand, unmanipulated flowers did produce seeds and this implies that $N$. africana can reproduce through autogamy. Future research, however, should test seed viability.

Pollinator preferences for different Nicotiana species may be linked to traits such as nectar volume and concentration (Kaczorowski et al., 2005) and corolla length (Nattero and Cocucci, 2007). The self-compatibility and self-fertility indices suggest that $N$. africana is at least partially dependent on pollinators. In the case of $N$. africana, several floral traits point to pollination by moths: the pale, tubular corollas (Fig. 1) with abundant nectar $(22.3 \pm 4.1 \mu \mathrm{l} /$ flower, Marlin et al., 2014) because such pale flowers generally attract moths (Willmer, 2011), and the small emission of an aliphatic methyl ester from its foliage (Raguso et al., 2006), because this ester is also emitted by N. longiflora and Nicotiana plumbaginifolia, both of which are self-compatible and visited by hawkmoths (Raguso et al., 2003). Alternatively, several other traits of N. africana suggest pollination by sunbirds, including the lack of a distinct floral scent (Raguso et al., 2006), abundant nectar, slightly curved tubular flowers with an oblique mouth and with stamens far exserted and unilaterally positioned so as to touch the back of the head in a bird probing for nectar, and upright inflorescences with sturdy axes for perching. Nicotiana glauca is pollinated by hummingbirds in its native Americas (Schueller, 2004), whereas in South Africa, where it was introduced and has become naturalized, the species is pollinated by malachite sunbirds (Nectarinia famosa) (Geerts and Pauw, 2009). The nectar volume of $N$. africana and nectar sugar concentration $(23.1 \pm 5.4 \% \mathrm{w} / \mathrm{w}$, Marlin et al., 2014) are 
similar to the nectar properties of $N$. glauca (Galetto and Bernardello, 1993), suggesting that sunbirds would similarly be attracted to $N$. africana. In addition, $N$. africana differs from the Australian members of section Suaveolentes in having day blooming flowers, which further suggests sunbird pollination (Raguso et al.,

2006).

Self-pollination may be prevalent in situations where plant populations are isolated and/or occur in environments where pollinators are scarce (Anderson et al., 2001). The three main populations of $N$. africana are $50-160 \mathrm{~km}$ apart and separated by a hostile desert landscape, making the movement of pollinators between them difficult. However, sunbirds are able to fly considerable distances; the dusky sunbird (Nectarinia fusca) can cover distances of over $200 \mathrm{~km}$ (Craig and Hulley, 1994). Furthermore, the dusky sunbird has been recorded in the Namib Desert, with nest-sites alleged to remain constant in successive years at Spitzkoppe (Hockey et al., 2005); the distribution of these birds thus overlaps with that of $N$. africana. Sunbirds are the most likely pollinators to be associated with $N$. africana, but field observations are needed to confirm these predictions.

\section{Acknowledgements}

We thank Teresa Doroszewska (Institute of Soil Science and Plant Cultivation, State Research Institute, Poland) for supplying seeds of $N$. africana, and Braam van Wyk (Department of Plant Sciences, University of Pretoria) for helpful discussions. Paul Akkermans, Isabelle Buyens, and Nicola Wessels provided technical assistance. This study was funded by the National Research Foundation of South Africa (grant 73671) and the University of Pretoria. Funders were not involved in any part of the research, preparation of the manuscript or the decision to publish. All authors contributed to the writing of the article. SWN and KK conceived the experiment. JDSS and DM designed the experiment. DM performed the experiment. KK and DM analysed the data. All authors approved the final version.

\section{References}

Adler, LS. 2000. The ecological significance of toxic nectar Oikos 91, 409-420. Adler, L.S., Seifert, M.G., Wink, M., Morse, G.E., 2012. Reliance on pollinators predicts defensive chemistry across tobacco species. Ecol. Lett. 15, 1140-1148. Anderson,

G.J., Bernardello, G., Stuessy, T.F., Crawford, D.J., 2001. Breeding system and pollination of selected plants endemic to Juan Fern' andez Islands. Am. J. Bot.
$88,220-233$.

Craig, A.J.F.K., Hulley, P.E., 1994. Sunbird movements: a review, with possible

models. Ostrich 65, 106-110.

Craven, P., 2004. Nicotiana africana. In: IUCN 2012. IUCN Red List of Threatened Species Version 2012.2 (retrieved 9.06 .12 from). http://www.iucnredlist.org.

Galetto, L., Bernardello, L., 1993. Nectar secretion patterns and removal effects in three species of Solanaceae. Can. J. Bot. 71, 1394-1398.

Geerts, S., Pauw, A., 2009. African sunbirds hover to pollinate an invasive hummingbird-pollinated plant. Oikos 118, 573-579.

Goodspeed, T.H., 1954. The genus Nicotiana. Chronica Botanica, Waltham, Massachusetts, $536 \mathrm{p}$.

Herman, P.P., 1990. Nicotiana africana. In: The Flowering Plants of Africa, 51.

Plate2020.

Hockey, P.A.R., Dean, W.R.J., Ryan, P.G., 2005. Roberts - Birds of Southern Africa, seventh ed. The Trustees of the John Voelcker Bird Book Fund, Cape Town. 1296 p.

Kaczorowski, R.L. Gardener, M.C. Holsford, T.P. 2005. Nectar traits in Nicotiana section Alatae (Solanaceae) in relation to floral traits, pollinators, and mating system. Am. J. Bot. 92, 1270-1283.

Kessler, D., Bhattacharya, S., Diezel, C., Rothe, E., Gase, K., Sch“ottner, M., Baldwin, I.T., 2012. Unpredictability of nectar nicotine promotes outcrossing by humming-birds in Nicotiana attenuata. Plant J. 71, 529-538.

Knapp, S., Chase, M.W., Clarkson, J.J., 2004. Nomenclatural changes and a new sectional classification in Nicotiana (Solanaceae). Taxon 53, 73-82.

Lerch-Henning, S., Nicolson, S.W., 2013. Bird pollinators differ in their tolerance of a nectar alkaloid. J. Avian Biol. 44, 408-416.

Lloyd, D.G., Schoen, D.J., 1992. Self- and cross-fertilization in plants. I. Functional dimensions. Int. J. Plant Sci. 153, 358-369.

Marlin, D., Nicolson, S.W., Yusuf, A.A., Stevenson, P.C., Heyman, H.M., Krüger,

K., 2014. The only African wild tobacco, Nicotiana africana: alkaloid content and the effect of herbivory. PLoS One 9 (7), e102661. http:// dx.doi.org/10.1371/journal.pone.0102661.

Nattero, J., Cocucci, A.A., 2007. Geographical variation in floral traits of the tree tobacco in relation to its hummingbird pollinator fauna. Biol. J. Linn. Soc. 90, 657-667.

Payne, R.W., Welham, S.J., Harding, S.A., 2012. A Guide to REML in GenStat ${ }^{\mathbb{R}}$ for Windows ${ }^{\mathrm{TM}}$, fifteenth ed. VSN International, Hemel Hempstead, UK.

Raguso, R.A., Levin, R.A., Foose, S.E., Holmberg, M.W., McDade, L.A., 2003. Fragrance chemistry, nocturnal rhythms and pollination "syndromes" in Nicotiana. Phytochemistry 63, 265-284.

Raguso, R.A., Schlumpberger, B.O., Kaczorowski, R.L., Holtsford, T.P., 2006. Phylo-

genetic fragrance patterns in Nicotiana sections Alatae and Suaveolentes. Phytochemistry 67, 1931-1942.

Saitoh, F., Noma, M., Kawashima, N., 1985. The alkaloid contents of sixty Nicotiana species. Phytochemistry $24,477-480$.

Schall, R., 1991. Estimation in generalized linear models with random effects.

Bio-metrika 78, 717-727.

Schoen, D.J., Lloyd, D.G., 1992. Self- and cross-fertilization in plants. III. Methods for studying modes and functional aspects of self-fertilization. Int. J. Plant Sci. 153, 381-393.

Schueller, S.K., 2004. Self-pollination in island and mainland populations of the introduced hummingbird-pollinated plant, Nicotiana glauca (Solanaceae). Am. J. Bot. 91, 672-681.

Willmer, P., 2011. Pollination and Floral Ecology, first ed. Princeton University Press, Princeton, New Jersey. 778 p. 